\title{
Synectics Learning and "Tringo" Model for Blended Learning System Application
}

\author{
Dedi Kuswandi \\ State University of Malang, Indonesia \\ dkuswandi08@gmail.com
}

\author{
Henry Praherdhiono \\ State University of Malang, Indonesia \\ henry.praherdhiono.fip@um.ac.id
}

\author{
Anselmus J. E. Toenlioe \\ State University of Malang, Indonesia \\ anstoenlioe@gmail.com
}

\begin{abstract}
The rapid growth in the use of the web based technologies and communications have offered educators with opportunities to investigate the most suitable learning environments for their students' needs. The purpose of the present study was to develop a blended learning system which applied synectics learning model and "TRINGO" model advocated by Ki Hadjar Dewantara. These learning models will encourage the students to be able to think creatively and innovatively. The study was conducted with Educational Technology students, at State University of Malang, Indonesia. The study employed Borg and Gall (2003) research and design model. Results suggest the blended learning product is developed in accordance with the principles of instructional materials development. The product is supportive to the implementation of the curriculum and are within the control of the lecturers. The students can use them, and the product is recommended for use in the Educational Technology Program.
\end{abstract}

Keywords: blended learning, tringo, Dewantara, synectics, creative, inovative

\section{INTRODUCTION}

The students with the blended learning system start loosing drive in expressing the assignment. The summary result of Online Learning App System (Sistem Aplikasi Pembelajaran Online/SARPOL) in 2010 noted that approximately $87 \%$ of the students of Educational Technology Program (ETP), Faculty of Education (FoE), State University of Malang submitted the assignment given during and a week after the Midterm Test. Actually, in the Semester Study Plan (SSP) is written that all the assignment must have been uploaded two weeks before the Midterm Test. There is only about $12 \%$ of the students who completed and submitted the assignment on time. This indicates that the students' drive is decreasing individually and as a group, the result is even worse. $100 \%$ or all of the groups could not submit all the assignments on time, neither the activity after the Midterm test.

The identification result of the assignment process and evaluation also shows the dreadful condition. Students' participation in learning activity only happens when it is before the test. This causes difficulty in evaluating the students' assignment within blended system by the lecturers. Such condition is the leniency given by SAPROL TEP FIP and the students leverage the hectic activity in evaluating the students' assignment by the lecturers. The entire difficulty is caused by the submission is when the test is held and one week after the Final Test (Ujian Akhir Semester / UAS). Thus, the lecturers' evaluation on the students' assignment did not go well.

The students leverage the leniency through the Blended system made by the lecturers and always take advantage of the revision session which is created by the lecturers who use Blended system. Some reasons of why the students do so are not logically acceptable enough. First, the students who uploaded the individual assginment before the tests or when the tests are being held say that it is to drive them to study for the tests.
Second, studying and completing the assignment at the end of the submission time is one of the effort in facing both Midterm Test and Final Test. Therefore, the students in the developed activity forum always ask to extend the deadline of the assignment. Third, there are illogically acceptable reasons such as students' hectic activity with other assignment from other subjects and the difficulty in group interaction because the students are used to have direct interaction with other students instead of having online interaction.

The identification result shows that the students' difficulty in running Blended learning system is caused by the leniency of the blended learning system developed by ETP FoE. As stated by Soepriyanto (2012), the students with SAPROL system are given the opportunity to accelerate the learning according to their ability, but unfortunately it is not accompanied by monitoring the standard of minimum task achievement. Thus, the students of TEP FIP UM are not active at the beginning of the semester. The major participation appears only on some specific students. Schedule faulty on the activity of producing learning media causes less production time effectivity and efficiency. This effect on students' creativity in generating media becomes limited because of the faulty in scheduling media production.

Students' learning experience can be realized by driving the students' needs. According to Zimmerman (1989), the learners have the potency to develop learning set up by themselves. Self regulated learning refers to: (1) students' ability in setting up / studying by themselves; (2) taking the action needed for self learning; and (3) learning managing and evaluating as well as giving the self feedback and justification. Stubbe (2008) says that learners can set up by themselves and do the learning activity which leads to knowledge creation, better understanding and learning, with the condition of using process like monitoring, reflection test, asking questions, and self evaluation. 
Blended learning system which is the base of SAPROL TEP FIP UM has some problems such as: (1) how to bring the creative process to the awareness by developing explicit assistance like portfolio through synectics model approach which is packed digitally to generate creativity; (2) how to improve creative capacity in the form of students' creativity equalization, both individually and in group; and (3) how the learning steps to the creativity are based on learning activity, start from understanding what is being learned (ngerti), feeling the learning (ngroso), and then being able to realize the capability of understanding and feeling into real creative activity in the learning process and assignment (nglakoni) with the responsibility (self responsibility).

According to the explanation above, electronic portfolio can be improved by synectics learning model approach to record TEP FIP UM students' activity in using analogy to solve the learning problems. Synectics model approach is chosen based on Joyce (2009) opinion so that the students will not focus on the punishment given if they cannot generate a series of learning activity or completing the task lately. The students are given the opportunity to express themselves in the form of assignment documents. Learning management through production analogies which contains of portfolio documents is expected to increase students' participation and creativity. This is

because of the beauty of learning based on metaphoric analogy awareness which is developed by the students themselves in accordance to TRINGO concept (ngerti, ngroso, nglakoni) by Ki Hadjar Dewantara (KHD).

\section{METHODS}

The research method can be put in the chart as follows (Figure 1). The detail of each stage is as follows: (1) first stage, Analysis: Analyzing the learning content that is Learning Technology subject by considering all the learning aspects and web-based learning evaluation. The analysis is started from learning content, main learning key steps, and Learning Competency; a) the analysis is done for students on their ability in achieving the learning goals, (b) the identification of steps and sub-steps are illustrated in the Learning Task Mapping (LTM), including analyzing the steps of portfolio with synectics approach and Tringo concept in the learning. The next analysis step is analyzing the learning content as the last part of the second phase of the analysis. All the analysis steps then are put as Task Objective Assessment Blueprint (TOAB). In the WBID Model, TOAB is used as tool to match the goal and the evaluation items with assignment items in the steps of portfolio with synectics approach and Tringo concept online.
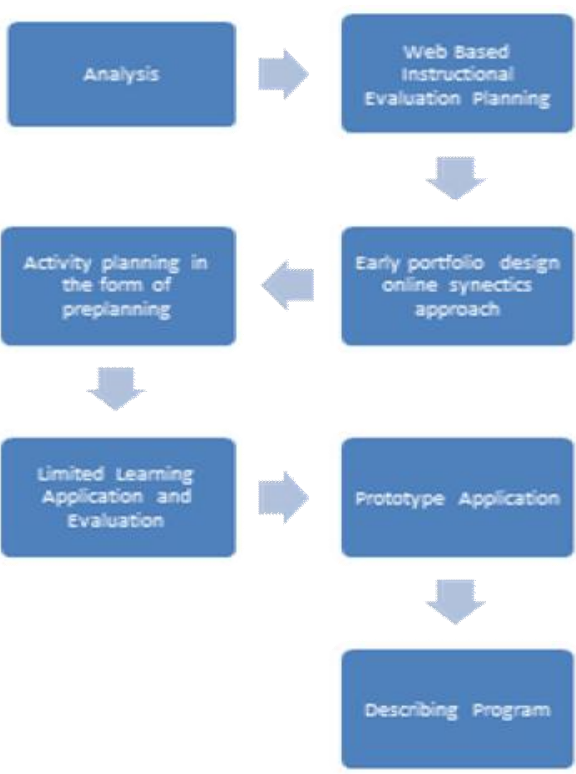

Figure 1

Development Stage

This early goal statement is reviewed and changes as needed for the learning development and the final goal. The findings from analysis stage will impact on WBI design stage, execution, and evaluation (Davidson: 2006); (2) the second stage is: Evaluation Planning of Web Based Learning portfolio model with Tringo concept synectics approach. There are two types of evaluation, that are formative and summative (Lee, 2004). In this stage, the researchers looked at the
Design of Synectics Portfolio Model, then developed the formative design of synectics portfolio model and summative evaluation plan of Synectics portfolio model. The evaluation design covers the initial condition, model prototype condition, and the result of WBI model prototype revision. The evaluation will capture all the things start and after the design stage, Synectics Portfolio Model implementation activity, that will recognized as field try out by 
Intertwined Design Synectics Portfolio Model Online. Due to the lack of application time, the summative activity is put out; (3) the third stage, the Design covers WBI initial Planning and Assignment Design. This design is started from the first stage activity, which is analysis. The analysis is done and the evaluation is planned, then designing online learning model and developed based on learning development phases. The design and development of the assignment is done simultaneously, which is known as collaborative design. In this stage, designing the learning model with synectics portfolio is done. The design starts from identifying the design, defining the goal, and determining the learning strategy and motivation. The development process then move from designing model to the synectics portfolio prototype model. Specifically, it is called as development phase; and (4) the fourth stage is preplanning activity, which covers the identification of assignment design, personel, and making the timeline for design and procedure development. Timeline explores various type of strategy evaluation and how to enhance based on TOAB with item goal and evaluation.

\section{RESULT AND DISCUSSION}

The students submit the portfolio as scheduled. The students who take Information System Management subject are individually able to show optimum performance by submitting the portfolio as scheduled. The time difference in submitting students' assignment is no longer in a span of weeks, but in days. The students have realized the importance of showing the assignment in the learning process. Synectics approach with KHD's tringo concept is related to metaphoric activity, creativity becomes a process that can be done consciously. The metaphors establish a comparative relation between an object or idea and other objects or ideas by exchanging the position. Systematically, the students are given the freedom to see other students' assignment. Through this system, the creative process occurs, which can connect something familiar with something unfamiliar or create new idea from ordinary ideas (other learners' assignment).

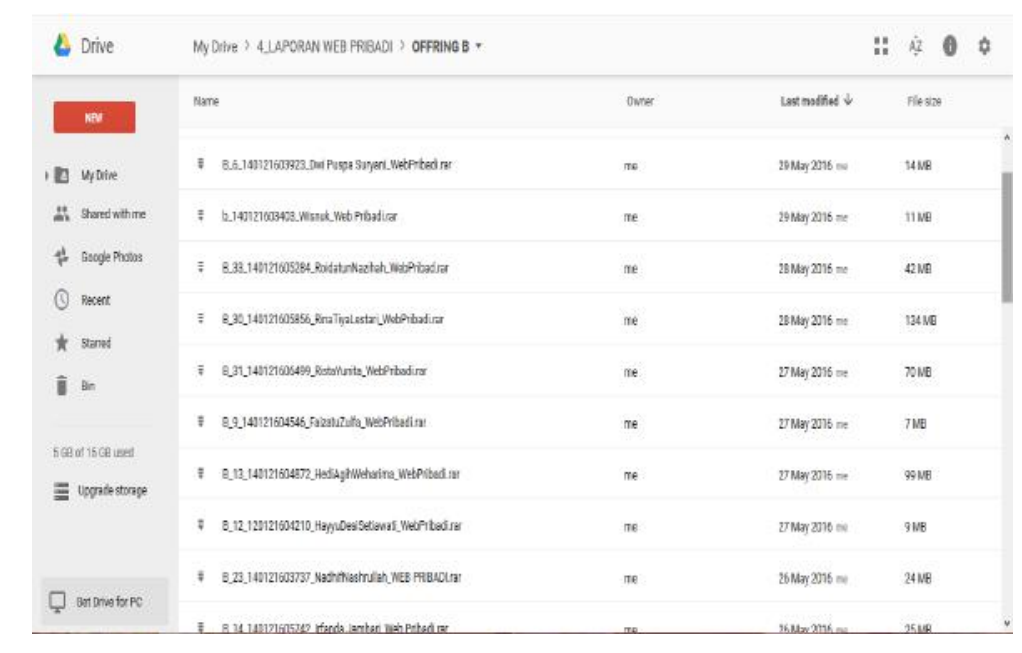

Picture 1

The Students Learning assignment

The students develop a personal website with an original idea. In the video data uploaded by the students in blended learning, the students upload assignment in the form of personal website development process. The students coherently explained from how the web is developed, the web content to the advantages of the website.

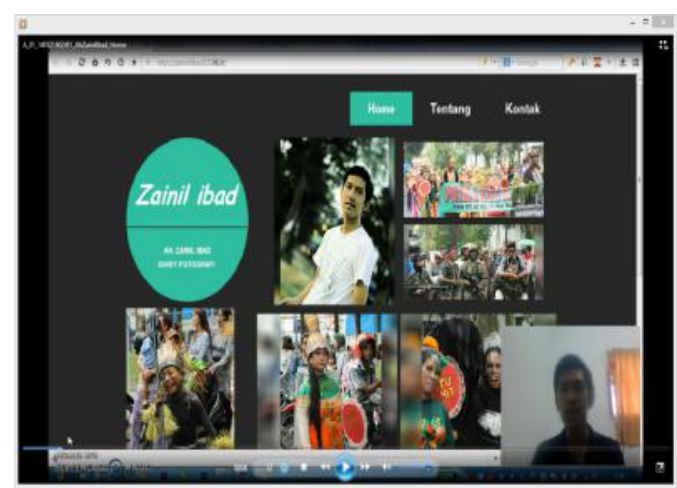

Picture 2

The students Video of Personal Website Development Process 
The students already have a high content metaphor. The students are able to introduce conceptual distance to other students with object or subject material, and encourage original thoughts. For instance, by asking the students to think of the website as a common learning resource, book, the students actually provide a metaphor structure, where the students can think of something familiar in new ways. Instead, the lecture can ask the students to think about new topics, learning website content, in the old way by asking them to compare it with Learning Management System. Metaphoric activity then depends on and comes from students' knowledge, helping them connect the ideas from familiar material to new ideas or view familiar material from a new perspective. Synectics strategies which use metaphoric activity are designed to provide a structure where the students can free themselves to develop imagination and insight in daily activity. There are three analogy types which are used as the basis of synectics exercise: personal analogy, direct analogy, and compressed conflict.

Synectics model requires the students to empathize with the ideas or subjects being compared. The students will feel that they have become a part of the physical elements of the problem. The essence of personal analogy is empatethic involvement. Personal analogy requires the release of personal identity into other rooms or objects. Greater conceptual distance is created by the loss of self or someone's identity (the students). This can only be done if the students are more creative and innovative in creating those analogies. The four stages of involvement in personal analogy on personal website development are corresponding to Gordon's stages (1957).

1. The first students' description of fact. The students talk about famous website, but do not present new ways of viewing an object and do not show empatethic involvement.

2. The first students' identification with emotion. The students talk about common emotions, but do not present new insight which the students are able to develop personal website.

3. Empatethic identification with living things. The students emotionally and kinesthetically identify analogy subject. The students give expression during portfolio video development which invites other students' empathy.

4. Empatethic identification with devices. This level requires full commitment. The students see themselves as an object and try to explore the problem. The students feel assisted by the learning devices around them, both software and hardware.

The purpose of introducing the levels of personal analogy is not to identify the form of metaphoric activity, but to provide guidance on how the best conceptual distance is built. The longer the distance, the closer students are to get new ideas. Synectics model with Tringo concept also creates a direct analogy which is a comparison of two objects or concepts. The comparison is not necessarily identical in all aspects. Its function is simple, that is to transpose the conditions of topics or problem situations that are exist in another situation to present a new perspective on an idea or problem. The first strategy to do is helping the students to view ordinary things in an unusual way using analogies to create conceptual distance. The objective of this strategy is to develop new understanding, empathize with/on attitude, design new entrance, and solve social or interpersonal problems.

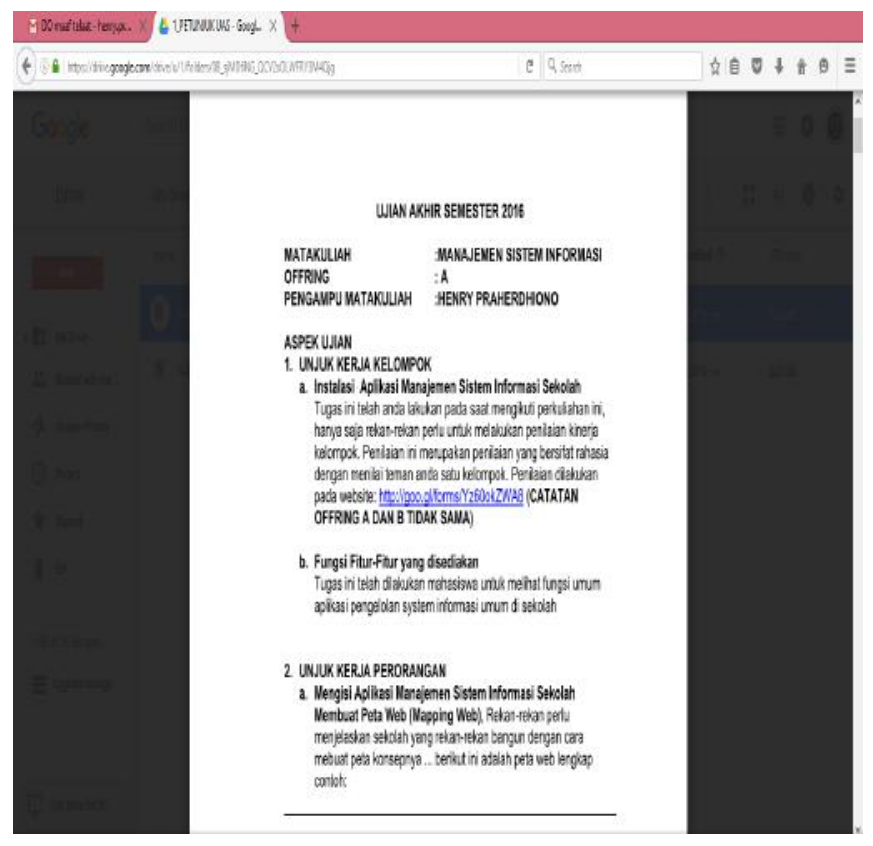

Picture 3

An Example of the Lecturer Giving the Beginning of the Portfolio 
Portfolio with synectics approach and tringo concept puts the lecturer to initiate a series of learning and guide the use of operational mechanism. The lecturer can help the students to make their mental process more intellectual. However, the students have the freedom in open discussion and they can engage themselves in solving metaphoric problem. The norms of cooperation, "fantasy game", and intellectual and emotional qualities are essential in building a setting in creative problem solving. The reward is internal, comes from students' comfort and satisfaction in learning activity.

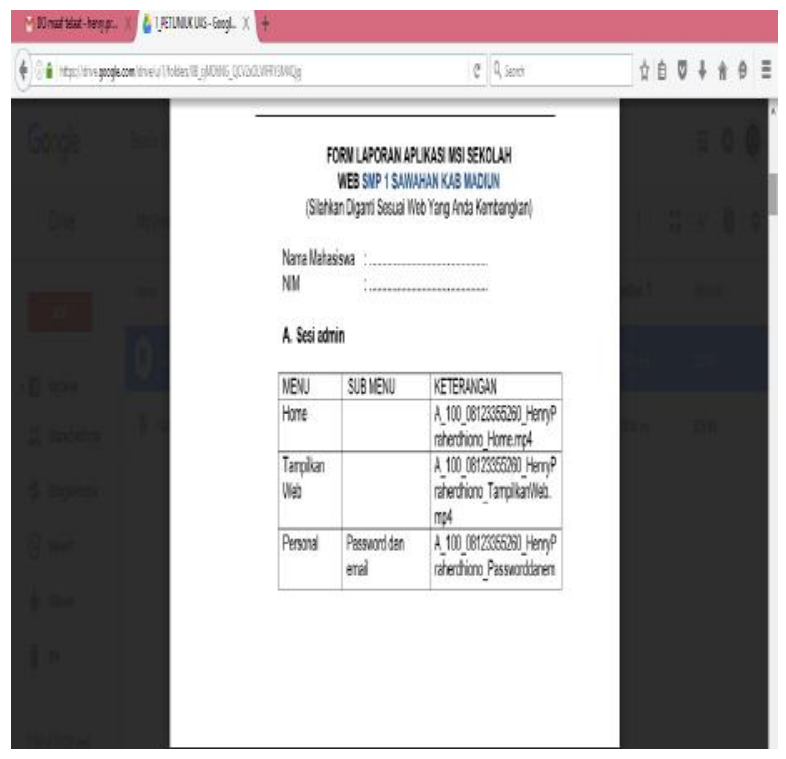

Picture 4

The lecturer gives learning initiative.

The lecturer pays attention to and reaches the students whose mindset need to be arranged. They also need to encourage the psychological conditions that might help to build students' creative response. Besides, the lecturer should use something irrational to encourage the students who are reluctant to spoil irrelevant things, fantasy, and other devices which essential to bring out the thought channels. In this model, the lecturer has an important role, thus they should learn to accept something strange and unusal. They should accept students' responses to make sure that the students feel that there is no external judgment against their creative expression. The more difficult problem to solve, the more important for the lecturer to implement and accept irrational analogies. Therefore, the students can develop fresh perspectives about the problem that they encounter.

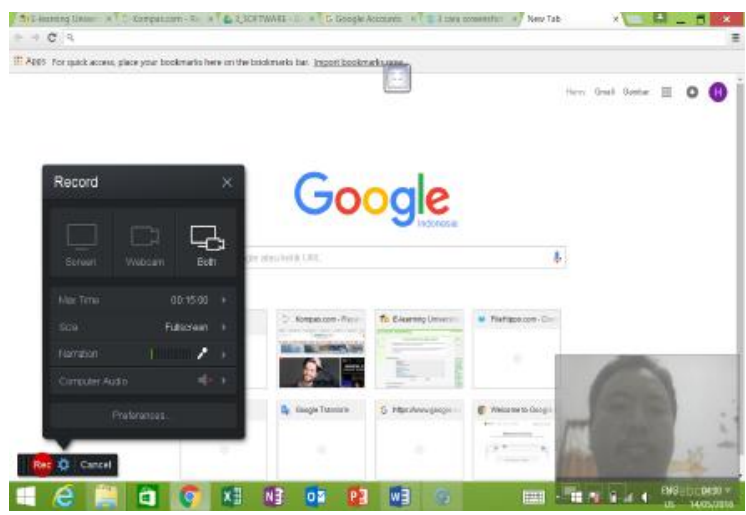

Picture 5

The lecture gives an explanation via the blended system

In the second strategy, the lecturer should be careful with early analysis. They need to clarify and summarize the learning activity development, and students' problem solving behavior development.
Essentially, the students still need the facilities from a leader who competent in designing and implementing analytical procedures. In terms of scientific or science issues, the students also need a laboratory where they 
can build other models and devices to make the problem more concrete and create other practical innovations. However, a class needs a working space where creativity is appreciated and used. The regular study room might provide those needs, but a class that is often designed in the form of groups might be too big for synectics activities. Thus, small group must be created.

Portfolio with tringo concept synectics approach increases individual and group creativity. Portfolio with tringo concept synectics approach can build a sense of togetherness among the students. The students learn about their classmates as they responded to an idea or a problem. An idea is seen as potential contribution in the group process. Tringo concept synectics procedures help create equal community where thinking is the single basis. Such exciting standard will certainly provide support for shy students.

Some results of the implementation of synectics model approach with tringo concept in the form of electronic portfolio in accordance to Joyce's opinions (2009): (1) Creative. The first strategy of synectics model approach can be applied directly to the creative portfolio because this strategy does not only stimulate the use of analogies, but also helps the students develop devices which can be used to do their tasks expressively; (2) Explore Learning Problems. The first strategy provides an alternative for exploring learning issues, especially issues with searchable standards and solutions. Metaphor creates distance, causing scientific confrontation between students that does not harm learners. The personal analogy stage is important in developing insight); (3) Problem solving. The objective of the second strategy is solving and conceptualizing problems using new ways in order to propose new approaches in personal life as well as in the classroom. There are many problems that can be used as a problem solving object, such as a social relation in class, peace in conflict, how to overcome the anxiety, how to feel better); (4) Create Portfolio Design or Product using The Synectics Approach with Tringo concept. A product is something that tangible, such as painting, building, or bookshelf, while design is a plan, such as party ideas or new ways in portfolio development; and (5) Expand The Students' Perspective About a Concept. Abstract ideas like culture and prejudice to internalized. Portfolio with Synectics approach and tringo concept is a great way to turn a familiar idea into a "strange" idea and vice versa.

Portfolio works effectively, especially for the students who experienced a regression in learning activities because of the fear to take any risk. Instead, the excellent students who only feel comfortable when giving response that they believe is true are often reluctant to participate in the learning activity.

\section{CONCLUSION}

Self-regulated learning development with electronic Portfolio using synectics approach and KHD's Tringo concept which creates students' participation and creativity equalization can be described as follows: (1) Whether individually or in group, online portfolio with synectics approach and tringo concept can improve students' problem solving capacity, expression, empathic creativity and insight. By bringing creative process into consciousness and developing explicit assistance to creativity, the students can directly increase creative capacity individually or in groups; (2) The students are able to describe creativity in the form of standard and organized development procedures in portfolio format with a synectics approach based on Tringo concept. Thus, the students are able to use that understanding to improve creativity. The creative process is describable, and this portfolio can train the students to directly improve their creativity. With tringo concept synectics approach, creativity is no longer seen as mysterious, intrinsic and personal capacity. Instead, the individual understands the basis of the creative process. They can learn to use that understanding to improve their creativity as they live and work, independently or as a member of group / society. Synectics model consciously makes the students able to describe that creativity by performing the training procedures; and (3) The students create an innovation and are able to share that innovation. Therefore, the students manage to solve a problem as personal experience and are able to share it with a group of student. Discovery or innovation which is considered creative is equal in all fields-art, science, and engineering-and is characterized by the same intellectual process. The researchers' idea might be different from the common belief. According to the common belief, creativity is only limited to art. In engineering and science, creativity is only called discovery or innovation.

\section{REFERENCES}

[1] Davidson, G., and Karen, R. 2006. Web-Based Learning Desain, Implementation dan Evaluation. New Jersey: Pearson Education Ltd.

[2] Gordon, W. J. J., and Bruner, J. 1957. Motivating the Creative Process. Paper delivered at the Second arden House Conference on Creative Process.

[3] Joyce, B., and Weil, M. 2009. Models of Teaching. New Jersey: Pearson Education.

[4] Lee, W. W., and Diana, L. O. 2004. Multimedia-Based Instructional Design. Peffieer: San Francisco.

[5] Soepriyanto, Y., Praherdhiono, H., and Adi, E. P. 2012. Mongkonstruksi Model Pengelolaan Kuliah Bersama Rumpun Matakuliah Sama Pada Karakteristik Lembaga Penyelenggara Berbeda. Research Report. Malang: State University of Malang.

[6] Zimmerman, B. J., \& Schunk, D. H. 1989. SelfRegulated Learning and Academic Achievement: Theory, Research and Practice. New York: SpringerVerlag. 